\title{
Mediação de leitura do literário no Ensino Médio: a leitura como acontecimento ${ }^{1}$
}

Gabriela Piske ${ }^{2}$

Adair de Aguiar Neitzel ${ }^{3}$

\section{Resumo}

Esta pesquisa objetiva discutir como as licenciandas do curso de Letras, bolsistas do Programa Institucional de Bolsa de Iniciação à Docência (PIBID), promovem a mediação de leitura do literário na Educação Básica. Entende-se que a mediação em leitura tem a capacidade de tornar-se um componente importante para aproximar leitor e livro, principalmente se faz-se uso da literatura pelo viés estético. Optou-se por um trabalho documental e exploratório, de caráter qualitativo, com dados coletados em portfólios, documentos institucionais, visitas in loco e grupo focal. A análise deu-se pela abordagem da reversibilidade de Roland Barthes. Constatou-se que as mediações priorizaram a exploração do texto literário pela via da fruição, além da sala de aula, oportunizando o diálogo sobre o texto. Palavras-chave: Mediação em leitura; Leitura do literário; Fruição estética; PIBID.

\section{Reading mediation of the literary in High School: reading as an event}

\section{Abstract}

This research aims to discuss how the teaching undergraduate students of the course of Portuguese Language and its Literature, scholarship holders of the Teaching Initiation Scholarship Institutional Program (PIBID), promote mediation of the literary reading in Basic Education. We understand that mediation in reading has the capacity to become an important component to approach reader and book, especially if the use of literature through an aesthetic bias is performed. We opted for a qualitative documentary and exploratory work, with data collected in portfolios, institutional documents, on-site visits and focus groups. The analysis was based on Barthes's (1997) approach to reversibility. We verified that the mediations prioritized the exploration of the literary text through the path of fruition, beyond the classroom, providing opportunities for dialogue about the text.

Keywords: Mediation in reading; Literary reading; Aesthetic fruition; PIBID.

\section{Introdução}

Na proximidade, sim, Encontro chão Retiro pão, sol da manhã partilho, na ceia da iniciação. Lindolf Bell

Proximidade; encontro; partilha. O poema de Lindolf Bell (2001) poetiza sobre a magia da aproximação - a qual permite o encontro e, por meio dele, a partilha -; mote de discussão neste

\footnotetext{
${ }^{1}$ Programa de Bolsas Universitárias de Santa Catarina - UNIEDU.

2 Universidade do Vale do Itajaí, Itajaí, SC, piskegabriela@gmail.com.

${ }^{3}$ Universidade do Vale do Itajaí, Itajaí, SC, neitzel@univali.br.
} 
artigo, a potência da mediação de leitura na formação de leitores. Entendemos que, quando esta não é diretiva, quando promove encontros, surgem novas possibilidades de envolvimentos, descobertas de vida. A proximidade de um sujeito mediador com um sujeito leitor, ou possível de ser leitor, promove o desejo pela leitura e amplia a potencialidade de um encontro capaz de gerar trocas entre ambos.

Mediação, na perspectiva de Darras (2009, p. 37), configura-se a partir da ligação de quatro elementos: "o objeto cultural mediado; as representações, crenças e conhecimentos do destinatário da mediação; as representações, crenças, conhecimentos e expertises do mediador e o mundo cultural de referência". A esses elementos, somam-se, ainda, "[...] os determinantes sociais ligados ao processo de transmissão dos saberes, dos valores, das emoções" (DARRAS, 2009, p. 37).

Na concepção de Darras (2009), a mediação é dependente do objeto. Isso significa que se o objeto é o texto literário, a mediação precisa ser diferente, por exemplo, de uma mediação feita sobre uma pintura, escultura ou fotografia. Cada objeto possui especificidades que precisam ser consideradas na hora de mediar. No que diz respeito às representações dos destinatários da mediação, o autor entende que os conhecimentos precisam ser considerados, assim como as expertises do mediador. Sua formação, suas vivências e suas compreensões vão interferir na forma como ele faz suas escolhas na hora de mediar. Além disso, o mundo de referência em que os indivíduos estão inseridos também tem influência no processo de mediação.

Na mediação dentro da escola, esses elementos estão presentes quando se une professormediador e aluno. Para mediar o objeto cultural livro, as histórias e as vivências de ambos os sujeitos interferem nas experiências que o literário poderá provocar em cada um. A formação do professor, seus conhecimentos acerca da literatura e sua intimidade com os livros são componentes que agem de alguma maneira sobre as ações mediadas e os efeitos nos sujeitos afetados.

Mediar exige um aproximar para conhecer de perto anseios, crenças, diferenças culturais dos envolvidos no processo. Com a aproximação, pode-se oferecer ao outro uma troca de saberes e provocar novas significações. Por intermédio da mediação, é possível abrir as brechas da intimidade do sujeito, pois ela "[...] aposta no estabelecimento de outro tipo de vínculo com o mundo, provocado pelas sutilezas de colocar em diálogo os sentidos, o sentimento, a razão e a atitude" (URIARTE, 2015, p. 53).

Periódico Horizontes - USF - Itatiba, SP - Brasil - e020047 


\section{HSE}

Mediar o texto literário é diferente de mediar um texto informativo porque estamos lidando com um objeto artístico (a literatura), o qual possui uma função estética, de tal forma que outro tipo de linguagem não é capaz, "como a discursiva e a científica" (BARBOSA, 2009, p. 21). Contudo, como mediar a arte que é para ser apreciada, e não apenas interpretada; que provoca desconfortos e questionamentos em quem a aprecia, que não tem a função de mostrar respostas prontas e soluções únicas? Arte que sensibiliza o sujeito para desenvolver diferentes percepções da realidade, exercitar a imaginação, ampliar a capacidade crítica e expandir conhecimentos; para educar esteticamente.

Neitzel et al. (2017) sinalizam que mediar está mais próximo de dialogar do que informar, porque precisa ser um movimento de escuta do outro, de perceber o outro, seu discurso e sua história. As pesquisadoras consideram que mediar exige do mediador suspender a narrativa porque essa narrativa precisa ser construída com o outro, de forma dialógica. Por isso, consideram que mediar é "[...] provocar o outro a construir proposições, a colocar pontos de interrogação" (NEITZEL et al., 2017, p. 330).

As autoras enfatizam que, diante de uma obra, o mediador necessita promover a nutrição estética, termo utilizado por Martins (2005) para denotar o envolvimento estésico entre obra e público. Para Martins (2005, p. 43), a mediação é um “[...] encontro, meio, estratégia, método para ensinar determinado conteúdo, ou, ainda, momento de refinamento cultural, percepção, que provoca trocas, nutrição e experiência estética, conhecimento para a apreciação ou processo de criação".

Tendo em vista essa concepção, passamos a investigar a atuação das licenciandas de Letras nas atividades desenvolvidas no Ensino Médio para discutir como elas promoveram a mediação de leitura do literário.

\section{Percurso metodológico}

Esta pesquisa documental e exploratória, de caráter qualitativa, é fruto de dissertação de Mestrado 4 e tem a finalidade de discutir como licenciandos do curso de Letras, bolsistas do

\footnotetext{
${ }^{4}$ Dissertação intitulada Encontros literários pela mediação em leitura, de Gabriela Piske (2017).
}

Periódico Horizontes - USF - Itatiba, SP - Brasil - e020047 
Programa Institucional de Bolsa de Iniciação à Docência (PIBID) de Letras promovem a mediação de leitura do literário na Educação Básica. Os instrumentos de coleta de dados foram: portfólios redigidos pelos licenciandos no decorrer do processo, disponibilizados no Ambiente Sophia plataforma virtual de acesso dos licenciandos e professores; documentos institucionais; visitas in loco à escola que os bolsistas atuavam; e grupo focal, realizado pelas pesquisadoras.

Os bolsistas eram compostos por seis estudantes de Letras, entre 6a e 7a fases - Clara Liz, Coraline, Cristina, Lara, Joyce Annie e Theodora Bryte ${ }^{5}$. A atuação do PIBID deu-se em uma escola regular de Ensino Médio, na cidade de Itajaí, Santa Catarina. Durante todo um ano letivo, foi realizado o trabalho de mediação em leitura junto a uma turma de $2^{\circ}$ ano, sempre às terças-feiras, no período noturno. As visitas in loco das pesquisadoras ocorreram durante um semestre letivo.

As ações em sala de aula foram planejadas previamente, em encontros na instituição de ensino, e tinham como proposta promover a leitura do literário de forma fruitiva, explorando diversas possibilidades de mediação. O grupo tinha o apoio de um professor supervisor da rede de ensino e uma coordenadora de área da universidade, ambos bolsistas da Coordenação de Aperfeiçoamento de Pessoal de Nível Superior (CAPES), que orientavam quanto a leituras e a materiais na preparação para a mediação, bem como acompanhavam o envolvimento e os resultados do que era desenvolvido na escola.

Quanto ao grupo focal, ele se deu em três momentos: atividade de planejamento e discussão de como as bolsistas mediariam dois textos literários pré-definidos; debate sobre perguntas pré-definidas acerca da temática deste trabalho investigativo; e debate sobre as ações de mediação em leitura desenvolvidas pelos dois grupos do PIBID, no decorrer do ano letivo de 2015. Todas as etapas foram registradas com o auxílio de câmeras filmadoras e gravadores de áudio e transcritas posteriormente.

A escolha pelo método de Grupo Focal deu-se pela necessidade de buscar informações complementares à pesquisa, não possíveis de serem encontradas nas outras formas de coleta deste trabalho. "O grupo focal permite fazer emergir uma multiplicidade de pontos de vista e processos emocionais, pelo próprio contexto de interação criado, permitindo a captação de significados que, com outros meios, poderiam ser difíceis de se manifestar" (GATTI, 2012, p. 9).

\footnotetext{
${ }^{5}$ Os nomes são fictícios e baseados na literatura. Visa-se, com isso, preservar a identidade das bolsistas.
} 


\section{HSF H O R I ON TES}

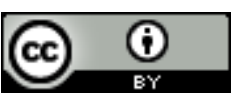

Para analisar esses materiais, foi necessário um método que contemplasse as diversas formas de um texto se manifestar. Todo discurso não se constrói sozinho; é uma compilação de leituras, de conhecimentos, de experiências, de conexões, de relações; está envolto em um eterno movimento que provoca significações e sensações, sem dar respostas prontas e fechadas, mas abrindo caminhos nas entrelinhas para diferentes descobertas.

Para tal, optou-se por uma abordagem metodológica que respeitasse as subjetividades das narrativas dos alunos, analisadas por meio da abordagem da reversibilidade de Barthes (1997), que compreende que um discurso se constrói no diálogo com o outro, em conexão com significações diversas, nas entrelinhas que expandem o olhar do pesquisador. Toda narrativa é dinâmica e descontínua porque ela obedece ao movimento da vida, cujos significados são construídos na experiência e, por isso, analisá-las exige do pesquisador uma disponibilidade de atravessá-las pela via da reversibilidade, olhando o movimento vivo no qual se insere o objeto estudado.

\section{A literatura como acontecimento}

Ensina-me sobra, sombra, terra, aonde me perdi. Ensina-me do orvalho que umedece o sonho de perfeição que não esqueci.

[...]

A minha aldeia chama-se: Ninho de liberdade. Mas onde terá ficado a asa da primeira idade? Lindolf Bell

No poema Asa da primeira idade, do qual se empresta o excerto da epígrafe, Lindolf Bell (2001, p. 83) aclama por ensinamentos em meio à liberdade, no "ninho da sua aldeia". Esse poema lembra-nos de que o texto literário tem uma função estética e que ele ensina, mas pelo viés artístico. Fazer uso dos ensinamentos citados pelo poeta permite-nos compreender que lidar com a arte na escola exige pensar o texto literário como arte, mediar o texto de forma a respeitar suas especificidades artísticas. Lindolf Bell era também educador e fez uso do poema para fazer falar seus pensares, mas com o compromisso de levar o poema como material a ser sentido,

Periódico Horizontes - USF - Itatiba, SP - Brasil - e020047 
percebido, experienciado, de forma que ele provocasse um encontro sensível entre leitor e texto.

Para Neitzel, Nova Cruz e Weiss (2017, p. 125), quando mediamos o texto como encontro sensível, a leitura é concebida como acontecimento, pois: “Pensar a leitura como acontecimento é um convite para entendermos sua força de afetamento, sua interferência na subjetividade do leitor, o processo de movência iniciado quando o leitor estabelece uma relação de fruição com o texto $[\ldots]^{\prime \prime}$.

É por intermédio da escola, que tem como principal mediador o professor, que observamos os ensinamentos "ganharem asas" rumo à formação do sujeito. O professor, que constrói diariamente a sua trajetória em sala de aula - em especial o de Língua Portuguesa e Literatura -, possui o papel de despertar nos discentes o interesse pela leitura e a sensibilidade para o literário, de mediar o texto como acontecimento.

Como um mediador, aquele que se torna peça fundamental no quebra-cabeça da formação de um leitor, o professor traz a sua experiência literária para a sala de aula e, com base nisso e no que a literatura pode fazer experimentar - como obra de arte para ser apreciada -, faz uso das mais variadas mediações para tornar possível a provocação junto ao texto, o contato entre o aluno e o livro; para estreitar a relação sensível do leitor com a literatura. Um ensino que desperte o olhar do leitor e resignifique a vida dos leitores em formação, que habite seu interior, que se mostre encarnada.

O contato com a literatura é uma das maneiras de provocar sensibilidade, de educar esteticamente, que "[...] consiste em ensinar o homem a olhar, escutar, movimentar-se, agir e experimentar, o que não ocorre de maneira natural e espontânea" (NEITZEL et al., 2012, p. 47), mas é resultado de construções culturais, e, por isso, a escola necessita ser esse espaço que desperta o desejo pelo texto, explorando mediações por meio dos encantamentos.

Segundo Petit (2009), o professor tem o papel de tornar mais familiar e confiante o contato dos alunos com os textos escritos. "Fazer com que sintam sua diversidade, sugerir-Ihes a ideia de que, entre todos esses textos escritos - de hoje ou de ontem, daqui ou de outro lugar - haverá certamente alguns que dirão algo de muito particular a eles" (PETIT, 2009, p. 217).

Saber como tornar as práticas leitoras reais na escola, despertando o interesse dos alunos e tornando a literatura algo possível de ser apreciada, como um professor-mediador, além da vivência literária, a formação acadêmica e profissional são elementos essenciais para o professor 


\section{HSF HORIZON T ES}

de Língua e Literatura. Para Lajolo (2007, p. 22), o professor deve ter familiaridade com o que transmite aos seus alunos:

O professor de Português deve estar familiarizado com a história do ensino da Língua Portuguesa no Brasil, com a história da alfabetização, da leitura e da literatura na escola brasileira. Afinal, só assim poderá perceber-se em um processo que não começa nem se encerra nele, e poderá, no mesmo gesto, tanto dar sentido aos esforços dos educadores que o procederam como ainda sinalizar o caminho dos que o sucederão (LAJOLO, 2007, p. 22).

Para aproximar alunos-leitores da literatura fruitiva, a mediação do professor é importante, pois, por meio dela, caminhos podem ser implementados de forma que eles entrem em contato com o universo literário e que se permitam sensibilizar-se com o livro como um objeto artístico. É pelo contato com a arte, que desafia o apreciador a enxergar a sua volta, que os sentidos ganham significações e que ele passa a ampliar as relações com o mundo. Por meio da mediação, a sensibilidade estética para com o texto é provocada, e isso ocorre quando "[...] ela pode ser exercida como fonte de liberdade e de autonomia por meio do encontro e do diálogo entre a arte e o público" (KUPIEC; NEITZEL; CARVALHO, 2016, p. 29).

Pela pessoa que medeia a leitura - ou um objeto artístico, uma arte -, o leitor pode ter seus primeiros contatos com a leitura e a literatura, quando isso não faz parte do seu cotidiano, ou se infiltrar mais a fundo nas obras literárias para "[...] nelas encontrar um sentido que lhe permita compreender melhor o homem e o mundo, para nelas descobrir uma beleza que enriqueça sua existência" (TODOROV, 2009, p. 33). No projeto do PIBID, Clara Liz, Coraline, Cristina, Lara, Joyce Annie e Theodora Bryte foram as mediadoras, e são as suas vozes que trazemos à baila.

\section{A potência de Machado de Assis}

Faço um poema. Me desfaço.

Me desfaço como um laço de uma caixa de presentes vazia. Lindolf Bell

A literatura, quando nos afeta, potencializa em nós pensares diversos que nos convidam

Periódico Horizontes - USF - Itatiba, SP - Brasil - e020047 
a rever nossos olhares sobre o mundo. Assim como o poeta se desfaz quando escreve um poema, conforme poetiza Lindolf Bell (2001), o leitor também se desfaz quando se entrega à literatura; quando se permite a estesia do texto literário; quando está aberto à aproximação do mediador; quando participa da mediação em leitura. Ele se desfaz para se refazer a partir de encontros, de descobertas, de interpretações e de sensações que se realizam entre a mediação e o contato com a literatura fruitiva.

Muitas são as ações que se desenvolvem na escola para aproximar as crianças e os jovens da leitura, porque a escola sabe que essa é janela para conhecimentos diversos, para apropriação, domínio e aperfeiçoamento da língua. No entanto, poucas vezes a literatura na escola é percebida como material artístico que possibilita e amplia a educação estética do leitor. Entendemos por educação estética a educação integral do ser humano, a forma como apreendemos o mundo, pelo sensível e pelo inteligível, sem apartamentos porque percebemos o mundo pelos sentidos, e a sua compreensão nunca se dá apenas pelo racional.

Schiller (2002, p. 113) convida-nos a perceber que a educação estética é um dos estágios para o homem chegar ao estado de autonomia intelectual, e que: "Não existe maneira de fazer racional o homem sensível sem torná-lo antes estésico". Tendo em vista essa compreensão, buscaremos discutir como as licenciandas do curso de Letras promovem a mediação de leitura do literário na Educação Básica, se elas fazem uso da literatura para educar esteticamente, se as mediações propostas possibilitam o refinamento estético do qual nos fala Duarte Jr. (2010). O grupo do PIBID que atuou com alunos do Ensino Médio regular desenvolveu ações de leitura para abrir espaços fruitivos à estesia?

Os encontros mediados por bolsistas em processo de formação docente ocorreram uma vez por semana, tendo como objetivo ampliar o contato dos alunos-leitores com a literatura clássica, em especial a brasileira. Escolheram, assim, promover encontros de leitura da obra de Machado de Assis, autor escolhido pelo grupo de bolsistas antes de iniciar as ações na escola.

A primeira ação do PIBID em sala foi aplicar um questionário-diagnóstico, com o objetivo de traçar um perfil leitor de cada estudante. Os dados foram utilizados para estabelecer "estratégias de leituras, explorando as deficiências [...] evidenciadas", explicou Coraline. Segundo Theodora Bryte, "para percorrer os caminhos da leitura" é preciso investigar "os gostos e as necessidades culturais desses estudantes". 
O questionário-diagnóstico desenvolvido e aplicado pelas pibidianas vai ao encontro do que Darras (2009) elenca como os elementos da mediação. Além do objeto mediado, do mediador e do mundo cultural, o autor evidencia que as "[...] crenças e conhecimentos do destinatário da mediação" (DARRAS, 2009, p. 37) também são fatores que influenciam no processo de mediar. Quão leitores são os alunos? Quantos livros eles leem em média? Que tipo de livros eles estão habituados a ler? Best-sellers, autoajuda, livros em quadrinhos, romances, poesias? Os estudantes costumam ler clássicos? Leem somente na escola ou fora dela também?

Conhecer o perfil de leitores trata-se de uma estratégia importante para auxiliar o professor-mediador nos caminhos a traçar para trabalhar a literatura em sala de aula, pois "[...] cada leitor, na individualidade de sua vida, vai entrelaçando o significado pessoal de suas leituras com os vários significados que, ao longo da história de suas leituras, este foi acumulando" (LAJOLO, 2007, p. 107).

Com o questionário-diagnóstico aplicado e a descoberta de alunos com pouco contato com livros de literatura, as licenciandas partiram para a primeira estratégia com as turmas: leitura, para introduzir a escrita de Machado de Assis. A leitura sendo o foco teve seu espaço logo no segundo encontro com os estudantes. Assim, antes de apresentar o escritor e abordar os movimentos literários, as bolsistas proporcionaram aos alunos a aproximação inicial com o texto. Ação que concorda com Martins (2014a) quando ressalta que a mediação é proporcionar encontros estéticos e não somente ensinar sobre a construção artística e o seu autor.

Para introduzir a literatura do escritor brasileiro, elas escolheram diversas poesias escritas por ele. Apresentadas em vários papéis cartonados que chamavam atenção pela cor laranja, todas foram distribuídas sobre as mesas em que cada licencianda se encontrava para serem selecionadas pelos alunos para leitura. Os alunos dividiram-se formando diferentes grupos, cada grupo coordenado por uma bolsista que os auxiliou na interpretação do texto. "Apresentamos aos alunos poesias de Machado de Assis, para leitura silenciosa dos poemas, após a leitura conversamos sobre os temas encontrados e os significados que os poemas trouxeram para os alunos", explicou Clara Liz. Um encontro que priorizou a leitura individual e a troca de impressões entre os membros dos grupos. "Assim abrindo um leque de discussão, das várias ambiguidades que os textos nos referiram", comentou Cristina.

Para Cristina, foi uma noite para dar "continuidade ao verdadeiro intuito" do projeto do 
PIBID: "formar leitores pela leitura fruitiva". O resultado ressignificou conceitos sobre a leitura. "Uma aula tão singela aos olhares externos, mas tão importante para todos os anos de estudo. A proposta da aula inclui apreciar os poemas de Machado de Assis e crescer em fruição $e$ vocabulário", acrescentou Clara Liz. "A arte, as expressões, os aspectos emocionais $e$ sentimentais foram as impressões perceptíveis relatadas pelo grupo. Momento bastante elucidativo e participativo", relatou Theodora Bryte. Lara sinalizou os "aspectos" promovidos pela leitura:

Percebeu-se que todos os estudantes de alguma maneira se identificaram com o texto escolhido, no momento, lembro-me de uma estudante que, ao ler o poema, "A Carolina querida, ao pé do leito derradeiro" [...] revelou que o autor conseguiu transmitir o sentimento de saudade, do amor, e da perda.

A mediação, para aproximar o aluno da literatura, não se concretiza quando o contato com o texto não é incentivado pelo professor-mediador. $O$ ato individual de ler e explorar as palavras que compõem uma obra literária é um caminho importante a ser seguido. Para ser um leitor, o indivíduo precisa ler. Passada a primeira mediação das pibidianas, de colocar os alunos diretamente em contato com o texto literário, desencadeou-se um processo de encantamento pelo texto literário.

É pela relação íntima entre texto e leitor que a proficiência linguística vai se constituindo, pelas interpretações que surgem, pela imaginação que flui, pelo olhar crítico que se manifesta, pelas descobertas que ganham espaços. A mediação contribui para mostrar caminhos que se aproximam desses resultados que a literatura propicia, mas cabe ao leitor, em sua individualidade com o texto, permitir-se desvendar o que a obra literária tem a lhe dizer.

Segundo Neitzel e Carvalho (2016, p. 149), “[...] a formação de leitores dá-se no silêncio do texto, na interação leitor/obra". Por isso, mediar o texto literário exige o exercício da escuta, como sinalizam Neitzel et al. (2017), pois uma mediação na perspectiva dialógica não pode ignorar o desejo do outro, seus sentidos e seus pensares. Mais do que comunicar, uma mediação literária necessita provocar.

Os poemas de Machado de Assis continuaram sendo explorados/mediados nos encontros. Os alunos tiveram a oportunidade de reler ou ler os que não foram lidos, mas em uma 
proposta um pouco diferente. A sala foi ambientada com um varal de réplicas de pinturas da época do Realismo, movimento literário do qual participou Machado de Assis. Essa ambientação visava a criar uma atmosfera que remetesse os alunos à época, ao contexto, aguçando, assim, sua curiosidade e criando um ambiente propício à atividade. Os poemas de Machado de Assis eram produções que atendiam às características do Romantismo - outro movimento do qual participou Machado - e que, de alguma forma, se afastavam ou se aproximavam das visualidades ali apresentadas.

Após a leitura, eles foram convidados a apreciar as reproduções das obras artísticas e "pediu-se que tentassem identificar o poema lido com as imagens", explicou Lara. Essa mediação levou-os a traçar relações do romantismo dos poemas com o realismo das pinturas. "Assim os alunos conseguiram encontrar na sua maioria, obras de arte [...] que representavam os poemas lidos ou lembravam os poemas, e falaram sobre o que viram na obra e no texto", relatou Clara Liz. Em seu portfólio, ao escrever sobre essa atividade, Theodora Bryte falou da importância de estabelecer relações e significados, "não se reduzindo apenas à objetividade da coisa, mas à função simbólica da linguagem, estimulando a sensibilidade estética, a produção de sentidos e o aspecto formativo do educando".

A leitura de obras visuais alarga o contato do leitor com o texto, ampliando sua percepção estética a partir da poesia, bem como de outras formas de manifestações artísticas, como a pintura. Ao trazer as obras para o espaço escolar, em um encontro voltado à literatura, as pibidianas contribuíram para ampliar as possibilidades de trabalhar a arte em sala de aula, como afirmam Carvalho et al. (2012) ao discutirem sobre a educação estética na prática escolar.

[...] propiciar ao aluno conhecer arte abre-se um caminho para que ele se aproprie de saberes culturais e estéticos inseridos nas produções e apropriações artísticas; além disso, possibilita o desenvolvimento do humano por meio da experiência sensível e criativa dos estudantes (CARVALHO et al., 2012, p. 18).

Promover uma leitura intertextual com poemas de Machado de Assis e pinturas, criando situações interpretativas e sensíveis além das palavras, colocou as pibidianas como "curadoras educativas", que, segundo Martins (2014a), são aquelas que operam mediações culturais. A curadoria educativa no espaço escolar ocorre quando o professor seleciona os materiais para

Periódico Horizontes - USF - Itatiba, SP - Brasil - e020047 
combiná-los e recortá-los de maneira que propiciem momentos plurais de encontros com a arte, de ampliação do olhar sensível dos alunos. "Um professor que cria curadorias educativas como ação provocadora e propositora, que abre espaços para silêncios e diálogos" (MARTINS, 2014b, p. 196), semelhante ao que as licenciandas realizaram, abre as perspectivas dos aprendizes a professores sobre a leitura, pois a curadoria amplia o pensar e o planejar, exige proposições abertas de leitura que dialogam com outras manifestações artísticas.

A leitura de textos de Machado de Assis fez parte de outros sete encontros do PIBID com os estudantes do 20 ano do Ensino Médio. Em dois deles, o objetivo foi ler o Conto da Escola. O local utilizado para a leitura no primeiro encontro foi a biblioteca, espaço que possui importância para ampliar as potências de uma mediação. A provocação para os afetamentos da arte ganha oportunidades plurais quando exploradas em espaços que vão além da estrutura física, que contribuem para sensibilizar esteticamente o olhar. Esse é o caso da biblioteca, que também é "[...] como um dispositivo de cultura, não apenas para pesquisa escolar, mas lugar de encontro" (BORBA, 2016, p. 51).

Martins (2018) e Borba, Neitzel e Carvalho (2016) enfatizam a biblioteca como um espaço de educação não formal que precisa ser mais explorada, pois mesmo a biblioteca escolar que está inserida no contexto da escola, muitas vezes é percebida apenas como repositório de livros. As pesquisadoras sinalizam que a biblioteca é um espaço de mediação cultural que necessita ser explorado, e seus sentidos, reinventados. Para as bolsistas, a compreensão da biblioteca como espaço propositor é importante porque ela enseja a possibilidade de mediações fora da sala de aula, alargando suas percepções sobre os espaços de aprendizagem.

Na mediação do PIBID na biblioteca escolar, diversas folhas com trechos do conto de Machado foram distribuídas sobre as mesas. Com todos reunidos, os alunos eram convidados a sentar aleatoriamente e pegar um dos contos para iniciar a leitura compartilhada. Cada papel continha uma numeração e uma orientação para a forma que deveria ser realizada a leitura, conforme contou Lara: "[...] os estudantes ficaram meio receosos, pois tinham que ler: rindo, chorando, declamando, etc. No início ficaram com medo, mas no decorrer da leitura se alegraram e gostaram das variedades que poderiam ler".

Momento de vivência que expõe as possibilidades da leitura ao explorar as palavras em diferentes formas e viabilizar condições para que haja o afetamento com o texto. Ler também é 
"[...] a capacidade do maravilhamento com uma rima, com uma construção frasal, com a beleza que as palavras, muitas vezes recriadas ou usadas num sentido não literal, podem proporcionar" (RITER, 2009, p. 53). Esses momentos de maravilhamento foram possibilitados pelo espaço propositor - a biblioteca - e pela mediação adequada que explorou formas de ler, oportunizando aos alunos o desejo pelo texto literário.

No segundo encontro, a leitura do Conto da Escola foi desenvolvida na sala de informática em grupos menores, tendo cada grupo como mediador de leitura um bolsista. Além dos bolsistas explorarem outro espaço propositor, eles puderam fazer uso de um aparato textual digital, o computador. Muitas são as experiências de leitura que fazem uso desse suporte e que validam o seu uso para ampliar a formação de leitores como especificam Neitzel et al. (2014) e Neitzel e Bridon (2013). Após a segunda leitura, desta vez feita no computador, os estudantes tiveram o desafio de reescrever o texto, trocando algumas palavras características da época machadiana por sinônimos contemporâneos. Essa atividade de leitura compartilhada viabilizou que os leitores interpretassem e ressignificassem o texto, aumentando sua proficiência linguística, mas também seu interesse pelo texto.

Nessa vivência leitora, as pibidianas criaram situações de leitura silenciosa, individual e compartilhada, espaço de trocas e de interpretações. Enquanto a leitura íntima entre indivíduo e texto é fundamental para constituir um leitor, a leitura coletiva, dividida entre grupos, torna-se uma etapa importante da mediação para ampliar o olhar dos leitores, para possibilitar encontros entre diferentes vozes, com variadas visões de leitura e, consequentemente, de mundo.

Para Riter (2009, p. 57), a formação do leitor na escola realiza-se a partir de dois processos que se interligam: "[...] momentos individuais e também espaços para troca, para partilha dos diferentes olhares". Colomer (2007) destaca que conversar sobre literatura com outras pessoas influencia na permanência de hábitos de leitura.

Compartilhar as obras [...] é importante porque torna possível beneficiar-se da competência dos outros para construir o sentido e obter o prazer de entender mais e melhor os livros. Também porque permite experimentar a literatura em sua dimensão socializadora, fazendo com que a pessoa se sinta parte de uma comunidade de leitores com referências e cumplicidades mútuas (COLOMER, 2007, p. 143).

Periódico Horizontes - USF - Itatiba, SP - Brasil - e020047 
A leitura compartilhada continuou sendo explorada em outros encontros do PIBID na escola. Em um deles, a proposta foi a leitura de fragmentos escritos por Machado de Assis. Sentados em círculos, os alunos receberam um número para ser sorteado e cada um deveria ler o trecho dos diversos selecionados. A partir da leitura, o aluno foi convidado a dialogar com o outro, ampliando olhares interpretativos.

Segundo Theodora Bryte, "as opiniões foram reflexos da atualidade, o que rendeu boas discussões. Cada um interpretou de uma maneira singular os temas contidos nas obras do século $X I X$, e que ainda são relevantes". Para Clara Liz, a dinâmica foi muito produtiva, uma vez que por meio "desse material os alunos puderam conhecer vários assuntos que Machado de Assis aborda em seus livros, além de expor suas compreensões, sobre estes textos que foram contemplados e lidos".

Essa mediação foi interessante para mostrar aos alunos a diversidade de criação de um escritor, que pode perpassar por diferentes gêneros, variadas formas e distintas temáticas. É nessa pluralidade de textos literários que o leitor tem a chance de se encontrar - ou se desencontrar, se desvendar, se redescobrir. Como ressalta Petit (2013, p. 62), cabe ao mediador contribuir para que os alunos-leitores apreciem "[...] a diversidade dos textos, fazê-los compreender que entre esses escritos de ontem e de hoje, daqui ou de outros lugares, certamente haverá alguns que terão algo a lhes dizer em particular".

Uma mediação dialógica possibilita que as experiências do outro sejam valorizadas. Tendo em vista essa ideia, as bolsistas organizaram outro momento de leitura compartilhada com o conto A Cartomante. Como provocar o desejo pela leitura, ajudar o outro a penetrar no texto? Muitas são as possibilidades e as pibidianas optaram pela discussão em grupo da temática do conto: cartomancia. "Foram dispostas questões sobre esse tema para alguns alunos, de forma sorteada para incentivar os alunos a uma conversa sobre o conhecimento e opiniões referente ao tema e sobre a leitura", explicou Clara Liz.

Após a discussão, os alunos fizeram a leitura coletiva do texto literário. Conforme relatou Clara Liz: "Após leitura de partes do conto, uma página de cada vez, foi feita a consolidação, conversando com os alunos sobre suas compreensões da história, identificando e socializando a história". Na opinião de Joyce Annie, esse momento de troca de impressões depois da leitura "demanda a resposta do leitor, explorá-la de diferentes maneiras e aspectos oportuniza o 
desenvolvimento da competência comunicativa, como também, desperta a apreciação pela obra literária". Esse depoimento denota que a bolsista possui clareza de que o inteligível não se dá apartado do sensível, e que a apreciação de uma obra literária pode desenvolver diversas competências essenciais ao falante de determinada língua.

Com esse encontro, podemos perceber a preocupação das mediadoras em realizar estratégias que ampliassem o contato com o texto pelo viés da fruição. Ao propor um debate sobre a temática do conto, antes de lê-lo com as interpretações que somente o texto literário pode provocar, elas comprovam as observações conceituadas por Riter (2009), que motivar consiste em criar ações para despertar o desejo na leitura. Evidentemente que uma boa mediação não objetiva apenas provocar o gosto pelo texto, mas propõe aberturas nele para a construção de novas significações, as quais ampliam as competências comunicativas do leitor, assim como sua educação estética.

Os últimos momentos de leituras compartilhadas ocorreram para apresentar aos estudantes leitores outros contos escritos por Machado de Assis. Cada bolsista escolheu um conto que mais se identificava para ler junto a um grupo de alunos: $O$ Enfermeiro (Lara), O relógio (Theodora Bryte), Entre Santos (Cristina), Pai contra mãe (Joyce Annie), A Igreja do Diabo (Coraline) e A chinela curta (Clara Liz).

As pibidianas tiveram a liberdade de conduzir seus próprios grupos de alunos para essa oficina dos contos. Todas realizaram diferentes ações de introdução à temática do texto, antes da inserção à leitura. Imagens, obras de arte e vídeos foram apresentados para propor discussões entre os presentes e para prepará-los à leitura compartilhada. O texto estava no centro do processo e não era pretexto para o ensino de qualquer outro conteúdo. A leitura era o componente curricular a ser desenvolvido e junto a ela a proficiência linguística se estendia.

Com a leitura realizada e com os alunos no processo de apropriação do texto, as licenciandas propuseram variadas estratégias de releituras dos contos, para que fossem socializadas no último encontro do PIBID do ano letivo na escola. Para ampliar as significações dos textos, assim como as suas percepções, os estudantes empregaram variadas linguagens. Divididos em grupos, produziram diferentes produtos: vídeo com imagens e frases que se interligavam ao texto; vídeo com leitura dramática resumida do conto; cartazes com gravuras e palavras; depoimentos sobre as leituras, que foram compartilhados em rede social da internet; 
e minicontos sobre o conto lido, também postados na internet e inspirados na caracterização do conto como uma das formas de escrever literatura.

Ao compartilharem interpretações textuais por meio de diferentes atividades articuladas e ao proporem incursões nos textos por meio da produção de objetos variados, as pibidianas contribuíram para ampliar a apropriação dos textos lidos e compreenderam que, quando o foco é a formação do leitor, o texto precisa ser o desencadeador das outras atividades. Ao fazerem uso de recursos contemporâneos, que casam com os gostos dos jovens atuais, como a produção audiovisual e a internet, deu-se a oportunidade de ampliar a leitura por meio da exploração de intertextualidades que foram sendo tecidas pelos próprios estudantes. Aproximar os recursos que fazem parte do cotidiano juvenil da literatura pode ser um caminho motivador para estreitar a relação com o texto literário. É isso que comprovam os depoimentos das pibidianas a seguir:

- Percebemos que todos conseguiram absorver a essência de Machado de Assis nas suas apresentações ao enfatizar os detalhes em que o autor brinca com as atitudes dos seres humanos. (Lara).

- A leitura dos contos possibilitou penetrar em outro universo e a viver com ele, no pensar e refletir sobre ele. (Theodora Bryte).

- Percebeu-se o envolvimento de todos, consolidou-se o verdadeiro intuito, que foi o desenvolvimento de estratégias de leitura e fruição, estudantes lendo mais. (Cristina).

- O resultado foi surpreendente e gratificante. E para encerrar, fica a palavra de um destes alunos. "O texto de Machado de Assis nos faz pensar, nos prende a atenção...". (Clara Liz).

E não é isto que precisamos na escola, que um texto faça pensar e atravesse o leitor? Que as mediações possibilitem a ampliação dos leitores na escola e que se tornem experiências sensíveis, a literatura vivida como acontecimento, conforme afirmam Neitzel, Nova Cruz e Weiss (2017)? Essas falas das pibidianas revelam que, além de todos os momentos de leitura, os encontros das bolsistas do PIBID com os estudantes criaram espaços de intertextualidade com os textos lidos. Houve uma preocupação no ato de mediar em apresentar características de escrita de Machado, assim como de trazer dados sobre sua história e acerca dos movimentos literários da época, século XIX e século XX, além de temáticas que Machado abordou por meio da sua literatura.

Contudo, entendemos que as atividades propostas acerca do autor e de sua obra foram 
centradas na leitura e na fruição, tendo o texto como foco principal. O texto não foi pretexto para o estudo do movimento literário, mas este veio à tona para ampliar as possibilidades de entrada no texto machadiano.

Muitas são as oportunidades que os alunos têm de se tornar leitores na escola. Weiss (2016) apresenta bons exemplos de mediações em leitura centradas no texto, que se ocupam com a apropriação do texto pelos leitores. Mediações que visam estabelecer uma relação de fruição entre leitor e obra, como ao trabalhar com escritos de Clarice Lispector e Virginia Woolf com alunos do 9 ano do Ensino Fundamental, priorizando o contato da literatura com o leitor, propondo atividades de exploração do texto que possibilitam a educação estética assim como a proficiência leitora. Weiss (2016) compartilha da experiência sinalizando que elas foram fruto de boas mediações literárias e que estas colocaram os alunos em uma posição de diálogo, sem medo de dividirem suas dúvidas e entendimentos sobre o texto:

Estava presente, evidenciada pelas ações positivas dos alunos, a aceitação da atividade. A postura do professor mediador influenciou na recepção da obra. A proposta foi se construindo com os alunos que se sentiam à vontade diante do texto, de explicitar seus não entendimentos (WEISS, 2016, p. 86).

Compreendemos que uma mediação literária adequada é aquela que coloca o leitor desejante para adentrar o texto e que lhe oportuniza discutir o texto, expor sua interpretação, enxergar outras possibilidades de sentidos que vão se mostrando pela leitura, como sinaliza Theodora Bryt: "Trazendo esses subsídios para a leitura, temos o intuito de chamar esse estudante para que abstraia os sentidos e abra uma porta para outro mundo, por meio dessas narrativas do autor". Mediações que incentivam a produção de narrativas e que ofereçam aos leitores trilhas que os levem ao encontro do texto, como narra Clara Liz. Para ela, a leitura literária com o objetivo de fruição na escola "precisa de espaços de reflexão, de momentos de conhecimento, uma discussão pura e simples, que permita ao leitor criar suas conexões e marcálo e, assim, ajudá-lo no caminho da leitura".

O percurso que pudemos identificar nos depoimentos das bolsistas evidencia que houve todo um movimento preocupado em despertar desejos nos alunos do Ensino Médio pelo texto, um desejo consciente de que é pela leitura do literário que ensinamos e aprendemos a gostar de ler, mas também que oportunizamos a experiência da leitura como acontecimento. É essa 
experiência que nos afeta, que nos alça a explorar a força sensível e estética do texto e que nos movimenta também a explorar sua força inteligível; afinal, razão e sensibilidade não podem ser apartadas.

\section{Algumas considerações finais}

Percebemos que, para os encontros dedicados à leitura, produziram-se muitos materiais que auxiliaram os alunos a adentrar a literatura, como slides explicativos, vídeo sobre a história e a vida do escritor, curta-metragem inspirado em contos machadianos. A leitura dramática, silenciosa e em voz alta também foi contemplada e muitos momentos foram abertos à discussão.

Depoimentos que sinalizam dúvidas das licenciandas sobre mediar com a apropriação do texto ou com outros recursos além da obra literária atestam que as futuras professoras trilham caminhos ainda não totalmente seguros. No entanto, são falas que também mostram mediadoras preocupadas em propiciar encontros com a literatura em sala de aula de diferentes maneiras, com variadas mediações.

Leitura individual; leitura coletiva; intertextualidade; fruição; arte; estesia; diálogo; silêncio; literatura; poesias; contos; Machado de Assis; mediação. Palavras-chave que se conectam, compõem-se em uma grande cadeia de encontros de professoras-mediadoras em processos de formação com alunos possíveis de se constituírem leitores. Durante os encontros dentro da escola em que Clara Liz, Coraline, Cristina, Lara, Joyce Annie e Theodora Bryte permaneceram por um ano letivo, com as mesmas turmas, o mesmo grupo de alunos, as licenciandas abriram espaço para ocupar as aulas com literatura, com leitura, com mediações que eram planejadas para aproximar alunos de um dos maiores nomes literários do Brasil.

Nosso objetivo foi discutir como as licenciandas do curso de Letras - bolsistas do PIBID promoveram a mediação de leitura do literário no Ensino Médio. Em síntese, podemos sinalizar como resultados que as mediações das licenciandas priorizaram a exploração do texto literário pela via da fruição, buscaram ocupar outros espaços para além da sala de aula e oportunizaram mediações de leitura que possibilitaram o diálogo sobre o texto. As propostas de entrada no texto deram-se por meio de leitura silenciosa, em voz alta, leitura dramática e por meio da

Periódico Horizontes - USF - Itatiba, SP - Brasil - e020047 
produção de vídeos.

Ao mediar os textos literários com o propósito de ampliar a percepção dos alunos por meio da apreciação, ao proporcionar as livres interpretações, ao abrir brechas para que fossem tocados e sensibilizados pelo que liam, sem ocupar-se em promover chaves de leitura, sem levar a caminhos únicos de significados dos contos, dos fragmentos e dos poemas, as pibidianas contribuíram para mostrar que a mediação em leitura pode auxiliar na constituição de leitores produtivos, leitores que estabelecem uma relação fruitiva com o texto e, por isso, compreendem a literatura como arte.

\section{Referências}

BARBOSA, A. M. Mediação cultural é social. In: BARBOSA, A. M.; COUTINHO, R. G. (orgs.). Arte/Educação como mediação cultural e social. São Paulo: UNESP, 2009. p. 13-22.

BARTHES, R. Elementos de semiologia. Tradução Izidoro Blikstein. 10. ed. São Paulo: Cultrix, 1997.

BELL, L. O código das águas. 5. ed. São Paulo: Global, 2001.

BORBA, A. N. Mediação cultural em bibliotecas. 2016. 162 f. Dissertação (Mestrado em Educação) - Universidade do Vale do Itajaí, Itajaí, 2016.

BORBA, A. N.; NEITZEL, A. de A.; CARVALHO, C. A mediação cultural: encontros, afetos e oportunidades. In: NEITZEL, A. de A.; CARVALHO, C. (orgs.). Mediação cultural, formação de leitores e educação estética. Curitiba: CRV, 2016. p. 91-106.

CARVALHO, C. et al. Arte no Ensino Médio: relações dos estudantes com Arte e Estética. In: NEITZEL, A. de A.; CARVALHO, C. (orgs.). Formação estética e artística: saberes sensíveis. Curitiba: CRV, 2012. p. 13-36.

COLOMER, T. Andar entre livros: a leitura literária na escola. Tradução Laura Sandroni. São Paulo: Global, 2007.

DARRAS, B. As várias concepções da cultura e seus efeitos sobre os processos de mediação cultural. In: BARBOSA, A. M.; COUTINHO, R. G. (orgs.). Arte/Educação como mediação cultural e social. São Paulo: UNESP, 2009. p. 23-52.

DUARTE JR., J. F. O sentido dos sentidos: a educação (do) sensível. 5. ed. Curitiba: Criar, 2010. 
GATTI, B. A. Grupo focal na pesquisa em ciências sociais e humanas. Brasília: Liber Livro, 2012. KUPIEC, A.; NEITZEL, A. de A.; CARVALHO, C. A mediação cultural e o processo de humanização do homem. In: NEITZEL, A. de A.; CARVALHO, C. (orgs.). Mediação cultural, formação de leitores e educação estética. Curitiba: CRV, 2016. p. 23-36.

LAJOLO, M. Do mundo da leitura para a leitura do mundo. 6. ed. São Paulo: Ática, 2007.

MARTINS, E. C. S. Potência cultural de quatro bibliotecas francesas: Bibliothèque de la Cité Internationale Universitaire de Paris (CIUP), Bibliothèque Sainte-Geneviève, Bibliothèque Publique d'Information Centre Pompidou (BPI) e Bibliothèque Nationale de France (BNF). 2018. 174 f. Tese (Doutorado em Educação) - Universidade do Vale do Itajaí, Itajaí, 2018.

MARTINS, M. C. Mediações culturais e contaminações estéticas. GEARTE, Porto Alegre, v. 1, p. 248-264, 2014a.

MARTINS, M. C. Curadoria educativa: dispositivos para encontros. In: MARTINS, M. C. (org.). Pensar juntos mediação cultural: [entre]laçando experiências e conceitos. São Paulo: Terracota, 2014b, v. 1. p. 188-202.

MARTINS, M. C. (org.). Mediação: provocações estéticas. São Paulo: UNESP, 2005.

NEITZEL, A. de A. et al. Formação estética na escola de ensino médio: algumas experiências. In: NEITZEL, A. de A.; CARVALHO, C. (orgs.). Formação estética e artística: saberes sensíveis. Curitiba: CRV, 2012. p. 37-54.

NEITZEL, A. de A. et al. Mediações culturais no museu. In: NEITZEL, A. de A. et al. (orgs.). Cultura, Escola e Educação Criadora: diálogos sobre experiências estéticas na educação. Itajaí: UNIVALI; Florianópolis: Dois por Quatro, 2017. p. 325-346.

NEITZEL, A. de A.; BRIDON, J. Poesia digital: reflexões em curso. Literatura y Lingüística, Santiago, n. 27, p. 111-134, 2013.

NEITZEL, A. de A. et al. Desafios da leitura e da escrita em meio digital. Revista lbero-Americana de Estudos em Educação, v. 9, p. 832-851, 2014.

NEITZEL, A. de A.; CARVALHO, C. A movência do leitor na leitura do literário. In: NEITZEL, A. de A.; CARVALHO, C. (orgs.). Mediação cultural, formação de leitores e educação estética. Curitiba: CRV, 2016. p. 143-157.

NEITZEL, A. de A.; CRUZ, D. V. N.; WEISS, C. A leitura do literário como acontecimento. In: NEITZEL, A. de A. et al. (orgs.). Cultura, escola e educação criadora: diálogos sobre experiências estéticas na educação. Itajaí: UNIVALI; Florianópolis: Dois por Quatro, 2017. p. 123-136.

PETIT, M. A arte de ler ou como resistir à adversidade. Tradução Arthur Bueno e Camila 
Boldrini. São Paulo: 34, 2009.

PETIT, M. Leituras: do espaço íntimo para o espaço público. Tradução Celina Olga de Souza. São Paulo: 34, 2013.

PISKE, G. Encontros literários pela mediação em leitura. 2017. 136 f. Dissertação (Mestrado em Educação) - Universidade do Vale do Itajaí, Itajaí, 2017.

RITER, C. A formação do leitor literário em casa e na escola. São Paulo: Biruta, 2009.

SCHILLER, F. A educação estética do homem. Tradução Roberto Schwarz e Márcio Suzuki. 4. ed. São Paulo: lluminuras, 2002.

TODOROV, T. A literatura em perigo. Tradução Caio Meira. 3. ed. Rio de Janeiro: DIFEL, 2009.

URIARTE, M. Z. O PIBID como espaço de mediação cultural: uma sinfonia. 2015. 250 f. Tese (Doutorado em Educação) - Universidade do Vale do Itajaí, Itajaí, 2015.

WEISS, C. S. A leitura do literário e a sala de aula: mediações em/de leitura. 2016. 160 f. Dissertação (Mestrado em Educação) - Universidade do Vale do Itajaí, Itajaí, 2016.

Recebido em agosto de 2018.

Aprovado em julho de 2019. 